\title{
Cura con plasma de úlceras tórpidas
}

\author{
Laura García Sánchez- Carme Font Senent - Esther Puigdemunt Melian
}

Clínica Girona. Girona

Para la cura de úlceras crónicas en los pacientes de nuestra unidad, decidimos utilizar métodos no convencionales. La cura con plasma ${ }^{1}$ ha demostrado que puede ser un tratamiento eficaz, por lo que iniciamos su uso con algunos de nuestros pacientes.

El primer caso con el que utilizamos la cura con plasma fue una mujer de 68 años en programa de hemodiálisis desde agosto de 2002, por una nefropatía diabética asociada a hipertensión. Presentaba dos úlceras, una en el brazo izquierdo producida por el rechazo a una prótesis de goretex. Después de pocos días de curarla con plasma, la úlcera mejoró y disminuyó su tamaño pero se decidió la extracción de la prótesis y limpieza quirúrgica de la zona por lo que no se pudo valorar un resultado final. La segunda úlcera, se localizaba en el maléolo externo del pie derecho. Apareció a finales del año 2004 y ante su aparición se inició el protocolo convencional de cura de úlceras de la unidad, sin conseguir que al cabo de un año la úlcera evolucionara favorablemente, por lo que previo frotis negativo de la úlcera, se decidió iniciar la cura con plasma.

\section{Protocolo de cura con plasma}

- Valoración del paciente: factores de riesgo para la aparición de úlcera, edad, hábitos tóxicos, higiene, estado nutricional y psicosocial, características de la diálisis y cambios en la bioquímica. Estos facto-

\footnotetext{
Correspondencia:

Laura García Sánchez

Cínica Girona

c/ Joan Maragall 26

17002 Girona
}

res hay que tenerlos en cuenta ya que pueden modificar o alterar los resultados de la evolución de la cura.

- Practicar un frotis al inicio de la cura que se repetirá cada vez que aparezcan síntomas que puedan indicar una infección.

- Observar y recoger información de la herida desde el inicio de la cura; para esto se diseñó una tabla en la que se anota el estadio, la forma, la medida, el color, el tipo de exudado y de tejido.

- La cura se hace una vez a la semana, si el apósito se encuentra limpio y conservado, o cada vez que aparezca exudado.

- Realizamos educación sanitaria a la familia, explicándoles el tipo de cura y sus cuidados, advirtiéndoles de la necesidad de avisarnos sobre cualquier problema (fiebre, dolor) que pueda relacionarse con la úlcera.

\section{Para la manipulación de la úlcera se siguen los siguientes pasos:}

1. Extraer $10 \mathrm{ml}$ de sangre del paciente, con un tubo estéril con 0,3 cm3 de heparina sódica, con una aguja y jeringa estéril.

2. El tubo se centrifuga en el laboratorio.

3. Se limpia la úlcera con Hibiscrub® jabón y se enjuaga con abundante suero fisiológico.

4. Secar con gasas estériles, sin friccionar, para evitar lesiones en el tejido nuevo. 
5. Extraer del tubo el plasma con una jeringa y aguja estéril. Procurar desechar el plasma de la parte superior del tubo ya que es el más pobre en células y proteínas.

6. Aplicar el plasma en la herida y colocar un apósito hidrocoloide, para favorecer la cicatrización.

7. Proteger con un vendaje sin presionar, para evitar fricciones u otras heridas.

\section{Evolución}

Tras evolucionar favorablemente, la úlcera, que se empezó a curar con plasma 25/1/06 desapareció completamente el 17/5/06 (figuras 1-2). Aunque encontramos alguna dificultad en la aplicación del plasma pues, al ser líquido costaba que se mantuviera encima de la herida, dificultado la adhesión del apósito. Consideramos que esta cura es beneficiosa, con un bajo coste, se utiliza un producto autólogo, lo que minimiza el riesgo de complicaciones y evita la cura diaria por lo que podemos concluir al igual que los autores que los describieron en esta publicación ${ }^{1}$, que este tratamiento puede ser muy beneficioso para paciente que presentan úlceras crónicas de difícil.

\section{Agradecimientos}

Nuestro agradecimiento a la paciente receptora de nuestras curas, y a las enfermeras de nuestro equipo por su profesionalidad, ya que sin ellas este trabajo no hubiera sido posible.

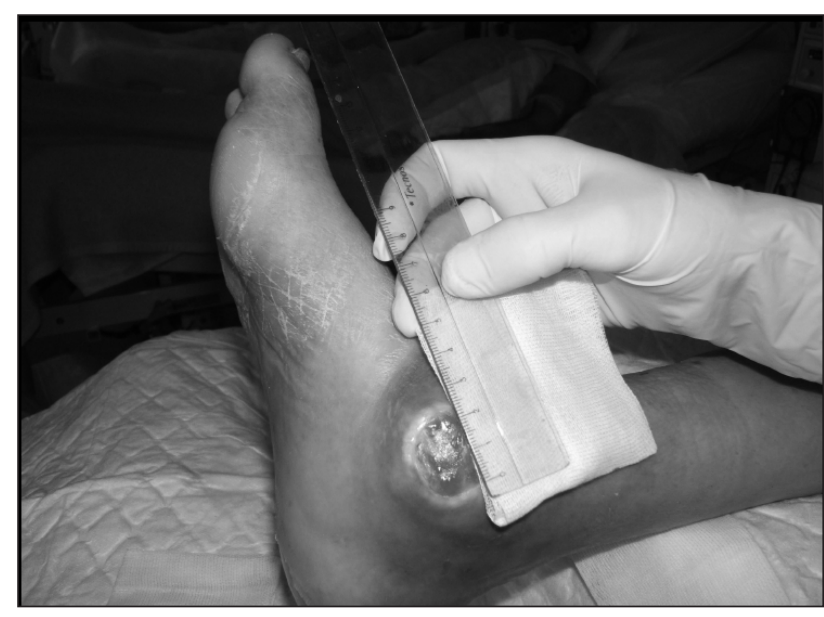

Figura 1 Inicio cura 25-1- 06

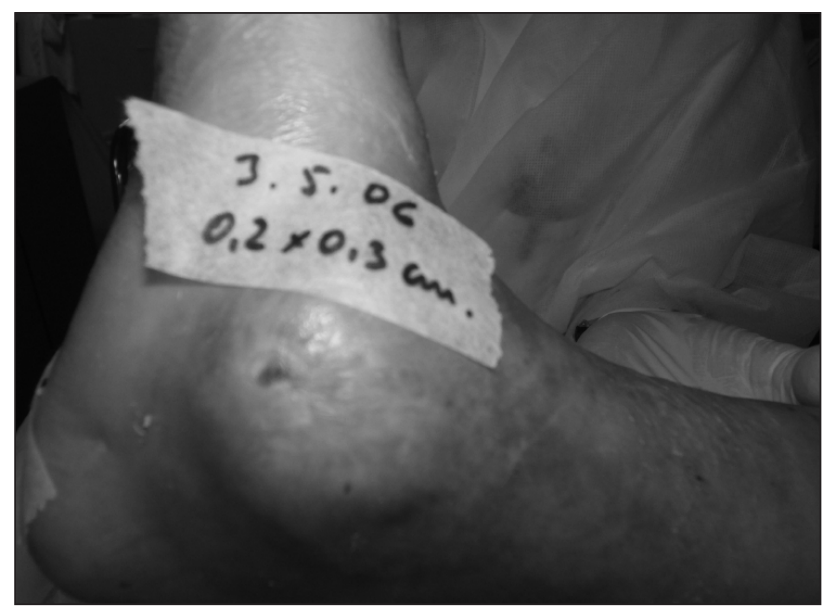

Figura 2. Fin cura 17-5- 06

\section{Bibliografía}

1. Cózar CM, Alcantud MJ, de la Prada F. Caso clínico: cura con plasma. Rev Soc Esp Enferm Nefrol 2005; 8(4): 332-334. 